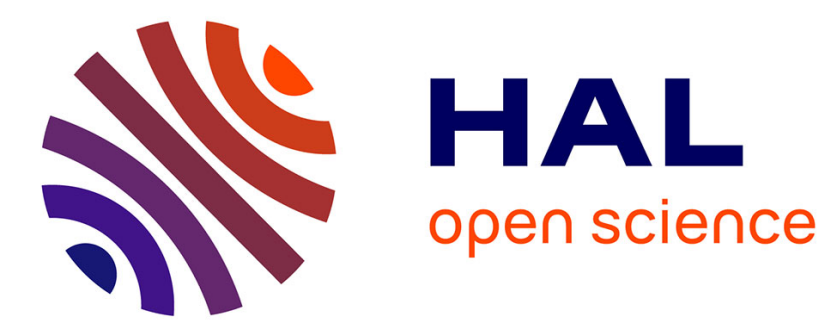

\title{
Evapotranspiration and surface heat fluxes over Belgium: outcome and perspectives
}

\author{
Françoise Gellens-Meulenberghs
}

\section{To cite this version:}

Françoise Gellens-Meulenberghs. Evapotranspiration and surface heat fluxes over Belgium: outcome and perspectives. Agronomie, 2000, 20 (8), pp.857-868. 10.1051/agro:2000163 . hal-00886086

\section{HAL Id: hal-00886086 https://hal.science/hal-00886086}

Submitted on 1 Jan 2000

HAL is a multi-disciplinary open access archive for the deposit and dissemination of scientific research documents, whether they are published or not. The documents may come from teaching and research institutions in France or abroad, or from public or private research centers.
L'archive ouverte pluridisciplinaire HAL, est destinée au dépôt et à la diffusion de documents scientifiques de niveau recherche, publiés ou non, émanant des établissements d'enseignement et de recherche français ou étrangers, des laboratoires publics ou privés. 


\title{
Evapotranspiration and surface heat fluxes over Belgium: outcome and perspectives
}

\author{
Françoise Gellens-MeulenBERGHS* \\ Royal Meteorological Institute, Research and Development Department, Hydrometeorological Modelling Section, \\ 3 avenue Circulaire, 1180 Brussels, Belgium
}

(Received 31 May 1999; revised 26 May 2000; accepted 27 June 2000)

\begin{abstract}
The assessment of the evapotranspiration and of the related surface turbulent heat fluxes is of major importance for atmospheric modelling and for practical applications in the field of agronomy and environment management. A method of assessment of these variables has been elaborated. As geostationary satellites can provide spatial information with a fairly short time step, the method combines ground meteorological data and Meteosat data. Hourly archives of evapotranspiration and surface turbulent fluxes covering the Belgian territory are now available for more than four years. Monthly means for the different years may be compared to characterise the climate variability. An outcome of the procedure is drawn and some statistics on the obtained results are presented. New perspectives offered by the next generation of meteorological satellites are outlined. In the following years, it is intended to further develop the method in the framework of the Land-SAF set up by EUMETSAT.
\end{abstract}

evapotranspiration / heat flux / Belgium / Meteosat / Land-SAF

Résumé - Évapotranspiration et flux de chaleur en surface sur la Belgique : bilan et perspectives. L'estimation de l'évapotranspiration et des flux turbulents de chaleur qui lui sont associés présente un grand intérêt pour la modélisation atmosphérique et pour les applications pratiques dans les domaines de l'agronomie et de la gestion de l'environnement. Une méthode d'estimation de ces variables a été mise au point. Afin de tirer parti de la possibilité offerte par les satellites géostationnaires de fournir des informations spatiales avec des pas de temps relativement courts, la méthode combine des données météorologiques observées à partir du sol et des données Meteosat. Des données d'archive horaires de l'évapotranspiration et des flux turbulents en surface couvrant le territoire de la Belgique sont actuellement disponibles pour plus de quatre années. Les moyennes mensuelles peuvent être comparées d'une année à l'autre pour caractériser la variabilité du climat. Un bilan de la procédure est esquissé et des statistiques sont établies sur les données obtenues. Les perspectives offertes par la nouvelle génération de satellites météorologiques sont soulignées. Il est prévu de poursuivre le développement de la méthode dans les prochaines années dans le cadre de la «SAF-Land »'EUMETSAT.

évapotranspiration / flux de chaleur / Belgique / Meteosat / SAF-Land

Communicated by Gérard Guyot (Avignon, France)

* Correspondence and reprints

F.Meulenberghs@oma.be 


\section{Introduction}

The partitioning of the available energy at the surface between latent and sensible heat fluxes plays an important role in the interactions between the Earth surface and the atmosphere. The actual evapotranspiration (AET), linked to the latent heat flux, is involved in both the water cycle and the energy balance at the surface. Indeed, large-scale synoptic patterns and meso-scale atmospheric structures determine the meteorological variables like the cloud cover, the surface radiation, the wind speed, the air temperature and humidity and, as a consequence, also the AET. In turn the AET and the surface turbulent fluxes act as boundary conditions influencing the characteristics of the atmosphere far above the surface in the so-called "atmospheric boundary layer" (ABL) [33]. Obtaining good estimates of the AET is thus of major importance in the field of climate and weather modelling. On the other hand, the assessment of the AET is potentially useful for a lot of practical applications in the field of agriculture, environment and land-use management.

\section{Scientific background}

Usual ground based meteorological data can provide only local AET values. Difficulties arise when attempting to obtain AET estimates at the meso-scale taking into account the heterogeneity of the surfaces. Recent efforts have concentrated on developing models that couple the surface fluxes and the atmosphere. Soil-vegetation-atmospheretransfer (SVAT) schemes have been elaborated and incorporated in both meteorological and hydrological models with different levels of complexity. As an alternative, the idea followed in the present research is to make use of remote sensing data to obtain information at the meso-scale. A method has been developed in this way at the Royal Meteorological Institute (RMI) to assess the actual evapotranspiration over the Belgian territory. The project has been funded by the Belgian Federal Office for Science, Technology and Culture
(Services of the Prime Minister) under its Telsat Programme during the period 1991-1995 [25]. It combines ground based meteorological as well as Meteosat satellite data.

Reviewing the literature related to the assessment of the evapotranspiration and of the surface turbulent fluxes is outside the scope of the present paper. The interested reader can refer for instance to Carlson [9], Choudhury [10], Norman et al. [48], Kustas and Norman [38] to find a general description and discussion about remote sensing approaches in this field. Only some broad guidelines will be recalled here. In such studies, the latent heat flux $L E$ is usually deduced from the surface energy balance equation

$$
R n-L E-H-Q_{g}=0
$$

provided that the other terms of the equation are known. $R n$, the net radiation, includes the contributions from the short and long wave radiation fluxes

$$
R n=(1-r) K_{d}+L_{d}-L_{u}
$$

where $r$ is the albedo, $K_{d}$ the visible irradiance (global, downward, solar radiation flux), $L_{d}$ the infrared irradiance (downward infrared radiation flux emitted by the atmosphere) and $L_{u}$ the infrared exitance (upward infrared radiation flux emitted and reflected by the surface). The heat conduction flux into the ground, $Q_{g}$, is often neglected at the daily time step or is assumed to be a constant proportion of the net radiation for shorter time steps. The sensible heat flux, $H$, may be expressed by the bulk aerodynamic method as

$$
H=\rho c_{p} *\left(T_{s}-T_{a}\right) / r_{a}
$$

where $\rho$ is the air density, $c_{p}$ its specific heat at constant pressure, $T_{s}$ the surface (aerodynamic) temperature, $T_{a}$ an air temperature higher in the socalled atmospheric surface layer and $r_{a}$ an aerodynamic resistance coefficient depending on several parameters (the atmospheric stability, the roughness of the surface, the friction velocity, etc.). The variables $R n$ and $T_{s}$ are estimated from satellite data, and $T_{a}$ and $r_{a}$ from ground based meteorological measurements. Many attempts have been made to obtain $H$ from relationship (3), mainly by making use of AVHRR data in spite of their low temporal resolution. 
The air temperature is usually observed above grass at a level of $1.5 \mathrm{~m}$ in the synoptic network. It may be spatially interpolated between synoptic stations in order to assess, by combination with the surface temperature, the difference $\left(T_{s}-T_{a}\right)$ for each pixel. The problem is complicated by the size of the pixels, covering heterogeneous surface types. In any case, the accuracy of this difference is of crucial importance for the assessment of the evapotranspiration. Furthermore, the radiative surface temperature provided by satellites is fundamentally different from the aerodynamic surface temperature; they can differ by a few degrees resulting in enormous errors in the estimate of $H[30,32]$. Further research is under way to establish relationships between them [48, 42]. To cope with these difficulties several researchers have adjusted empirically one of the parameters (the aerodynamic resistance, the roughness length, the emissivity, etc.) or have added an "excess resistance" to $r_{a}$, (see for instance [29]); others have developed and applied two-sources models [18, 49, 69]. The potentialities of the directional measurements of the temperature are still under study [39]. Other approaches attempt to avoid using the temperature difference $\left(T_{s}-T_{a}\right)$. For instance, Diak and Whipple [17] focussed on the temporal evolution of the radiative surface temperature used together with an ABL model. They pursued their researches, with the parametrisation of the diurnal growth of the ABL height in relation with the daily mean value of $H$ [44]. Numerous teams have investigated how to complement measurements of $T_{s}$ with the assessment of different vegetation indices introduced in empirical or physically based relationships (e.g. [3, 35, 45]). Others combine several approaches including SVAT schemes or ABL models (e.g. [2, 14, 27, 28, 43]). In a general way, many of these approaches are promising but have still to be applied and validated over extensive data sets. Very few are run operationally (e.g. [54]).

An alternative method, not using $\left(T_{s}-T_{a}\right)$ and thus expected not to be too sensitive to possible inaccuracy of the radiative surface temperature, has been developed at the RMI. In this method, the radiative surface temperature is only involved in the estimate of $L_{u}$. Moreover, the data processing has been achieved in an operational way by means of automatic procedures. After a short reminder of the methodology, some results, obtained after four years of monitoring, will be presented. New perspectives offered by the next generation of meteorological satellites will then be sketched.

\section{Materials and methods}

\subsection{Input data and assessment of the net radiation}

The methodology was elaborated in order to use as much as possible the meteorological information available in (quasi-) real time at the RMI. Meteorological data like radio-soundings, synoptic data and data sent by an automatic meteorological station are used. In the case of mid-latitudes, the AET is expected to be mainly driven by the available radiative energy at the surface, itself depending on the local cloud cover. Geostationary satellite data have been chosen in this research as they are able to follow with a high frequency the evolution of the cloud structures and of the diurnal radiative characteristics of the land surfaces. The Meteosat images are received at the RMI by means of a PDUS system. In the elaborated method, the hourly visible and infrared windows $(67 \times 32$ pixels) covering the Belgian territory are extracted from the original PDUS images with the infrared channel spatial resolution (around $9 \times 5 \mathrm{~km}^{2}$ ). They are used to assess the cloud cover and the surface components of the radiation budget.

The Meteosat PDUS numerical counts in the visible and the infrared channels are used to build reference images and histograms with one and two dimensions. First, the pixels of each slot are separated into cloud free regions (sea or land) and cloudy regions. Secondly, the available information at the synoptic stations is taken into account in the clustering [53] to obtain four cloud cover classes: cloud free, intermediate and intense nebulosity with either low or high top.

The calibration of the visible numerical counts is done by taking into account the coefficients obtained by Moulin et al. [46]. Then, an inversion 
procedure of the $5 \mathrm{~S}$ code [64] operating with radio soundings allows the albedo values to be obtained. The visible irradiance is obtained by a physical method following Brisson et al. [5]. Two different approaches for dealing with the infrared part of the net radiation budget exist: after the calibration step of the infrared channel, the Lowtran 7 code [36] and radio soundings are used to obtain the exitance and the irradiance values for the clear sky cases. When the sky is cloudy, empirical methods have been set up and make use of the cloud cover assessment. A detailed description of the net radiation evaluation may be found in GellensMeulenberghs and Roulin [22] and in Roulin et al. [55]. The surface net radiation $R n$ is then calculated by means of relationship (2) for each pixel.

\subsection{Turbulent fluxes: assessment at the reference station}

The evapotranspiration and the turbulent sensible and latent heat fluxes are first assessed at the level of the micro-meteorological station of Melle, located close to the central part of the country. This automatic station plays the role of reference station and is, at this time, the only one fully instrumented of the RMI stations network providing quasi-real time data. The latent heat flux is deduced from the surface energy balance equation while the sensible heat flux is estimated by means of the MoninObukhov similarity theory using the profile method [6]. The mean 30 minutes averaged values of the temperature and wind speed made at two levels ( 2 and $10 \mathrm{~m}$ on a mast) are used. Mean values over 30 minutes of the air humidity is also available. To check its validity, the method of assessment of the turbulent fluxes has been previously applied over one year (1995) of data recorded at the Cabauw site (e.g. [66]). It compares well with estimated fluxes obtained for this station.

\subsection{Assessment and characteristics of the evaporative fraction}

The evaporative fraction

$$
f=L E /\left(R n-Q_{g}\right)
$$

is the ratio of the latent heat flux to the available surface energy budget. It characterizes the partitioning of the available energy between the latent and the sensible heat fluxes. It has been the subject of several investigations during the last ten years (e.g. $[7,12,47,52,63])$. It is nearly constant during the daytime and is more stable than the well known Bowen ratio. Some variability seems to be possibly induced by cloudy weather or fronts, or the proximity to discontinuities of surface types. Some links may be expected with variables such as the soil moisture, the types of vegetation or the topography. However, little evidence from measurements has been found until now and no clear relationships have been established at this time between the evaporative fraction and these variables. Few comparisons of evaporative fraction values between different sites have been made. For instance, when considering only 4 golden days and 20 stations, Shuttleworth et al. [63] obtained a standard deviation of the order of 0.1. Following a transect across the boreal forest, Oncley et al. [51] noted that except for the lakes and the frozen tundra, the fluxes varied smoothly from the predominately deciduous forest to the coniferous forest and to the tundra.

In this study, a daily mean value $f_{d}$ of the evaporative fraction is computed at the Melle station by

$$
f_{d}=(L E)_{d} /\left(R n-Q_{g}\right)_{d}
$$

where $(L E)_{d}$ is the daily mean values of the latent heat flux and $\left(R n-Q_{g}\right)_{d}$ is the daily mean of the available surface energy budget. In the future, the intention is to compute it for several automatic stations in the RMI network, when they become available. In the mean time, and for the purpose of the present study, $f_{d}$ is assumed to be the index representative for all the Belgium territory for partitioning the available energy. This assumption seems acceptable since the evaporation fraction is particularly stable for humid temperate climate like the Belgium climate and since the Belgium vegetation cover does not vary too much over the country (Belgium is mostly covered by a mixture of grassland and crops in the central and western parts, while more forests (deciduous and coniferous) and pastures may be found in the eastern part). This 
hypothesis is also supported by the work of Sellers et al. [59]. To obtain a first insight into the spatial variability of $f_{d}$, the soil-vegetation-atmosphere transfer scheme in use in the daily step lumped RMIB hydrological model [8] has been fed by 20 years of daily data for 7 stations spread over the country and including the Melle station. The rootmean-squares and biases obtained are used as input in the sensitivity study (presented further in the text).

\subsection{Turbulent fluxes: assessment at the Belgium scale}

In a second step, the net radiation flux $R n$ estimated from Meteosat and meteorological data is combined with $f$ to assess actual evapotranspiration, for each pixel and each hourly slot during the daytime period, by the relationship

$$
L E=f_{d}\left(R n-Q_{g}\right) .
$$

As in many remote sensing approaches, $Q_{g}$ is assumed to be a constant proportion of $R n$ (equal to 0.1 when $R n$ is positive) $[11,15,50]$. As expected, the assessment of $L E$ in this way for the Melle station with ground measurements gives excellent results: using 30-minute mean ground observed values and a daily constant value $f_{d}$ for the 1994-1996 period, the bias is close to zero $\left(0.032 \mathrm{~mm} \cdot \mathrm{day}^{-1}\right)$, and the correlation coefficient and the Nash index are close to 1.0 [26].

\subsection{Sensitivity studies}

Sensitivity tests have been performed in Gellens-Meulenberghs and Roulin [23]. The adopted scenario of uncertainty for the investigated input variables was a root mean square error $(\mathrm{rms})$ corresponding to $45 \%$ of the mean observed value for $R n$ and to one degree for the temperature. Monthly bias and $r m s$ were assigned as errors to $f_{d}$ according to the results obtained above by means of the hydrological model. These uncertainties induce daily rms values of the AET between 0 and $2 \mathrm{~mm} \cdot \mathrm{d}^{-1}$. These errors present a large dispersion and reach their maximum during the summer.
During winter, the absolute errors are small but the relative errors can reach high peaks (more than $100 \%$ ) as the evapotranspiration rate is close to zero. The net radiation is the variable responsible for the major part of the error following this scenario. The fraction of evaporation contributes less to the total error but has a higher variability occurring during short spells of the year. Considered separately, the net radiation and the evaporative fraction induce respectively relative errors around 50 and $25 \%$ during the summer with the envisaged scenarios of the input data uncertainties. The air temperature error plays a negligible role on the assessment of the latent heat of evaporation $L_{v}$. Combining the different sources of errors envisaged implies a mean relative root-mean-error around $60 \%$. Other sensitivity tests have shown that the highest contribution to the net radiation comes from the global solar radiation $K_{d}$ and the lowest contribution is due to the albedo. The infrared irradiance $L_{d}$ can also imply an important contribution, especially during winter. In summary, the more critical variable is the net radiation. The evaporative fraction plays a secondary role, not introducing a too large error when considering only one reference station.

\section{Results}

The method has now been applied for more than four years, initiating a long term remote sensed monitoring. Operational aspects of the automatic data processing are discussed in GellensMeulenberghs and Roulin [24]. The analysis of the individual hourly images shows the importance of the clouds in the assessment of the evapotranspiration. Temporal means of the evapotranspiration may then be calculated on the daylight period and on the monthly basis by integrating the hourly evapotranspiration values. An analysis of some results interpreted in terms of synoptic conditions or of the variability of the climate may also be found in Gellens-Meulenberghs and Roulin [24].

Each hourly image covering the Belgian territory consists of 788 pixels inside a window of $67 \times 32$ 

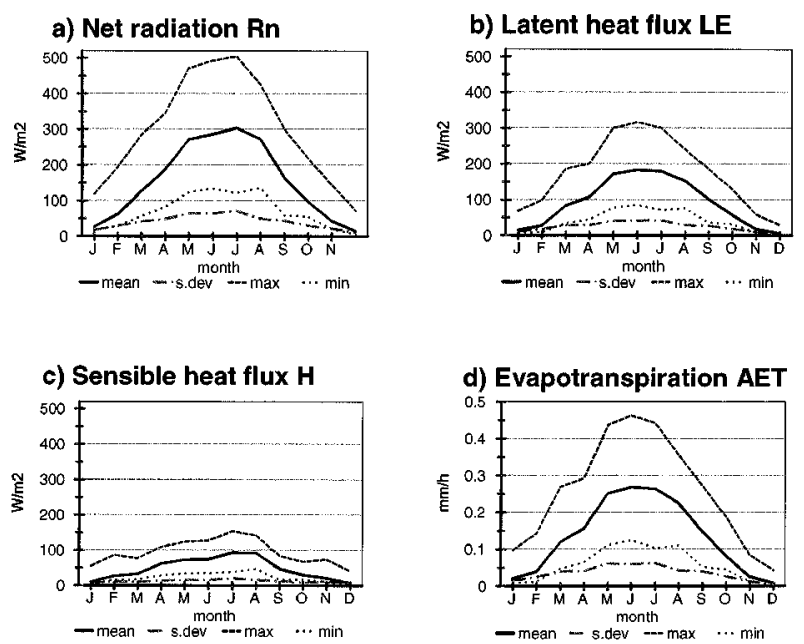

Figure 1. Monthly means of the hourly day-light values over the Belgian territory (1994-1997) deduced from Meteosat and meteorological data for the following statistics: areal mean, standard deviation, minimum and maximum. Net radiation (a), latent heat flux (b), sensible heat flux (c) and evapotranspiration (d).

pixels. Figure 1 shows the areal monthly means and standard deviations of hourly diurnal results for several variables: net radiation, sensible and latent heat fluxes and evapotranspiration [20]. The mean number of images involved during the day-light period ranges from 5 in winter to 10 during summer months. Between 2400 and 2900 hourly images have been considered each year. The output variables exhibit an important annual cycle. For instance, the mean hourly net radiation ranges between 20 and $300 \mathrm{~W} \cdot \mathrm{m}^{-2}$ with a mean standard deviation ranging from 15 to $70 \mathrm{~W} \cdot \mathrm{m}^{-2}$. The corresponding values for the evapotranspiration are in the ranges $0.02-0.27 \mathrm{~mm} \cdot \mathrm{h}^{-1}$ and $0.02-0.06 \mathrm{~mm} \cdot \mathrm{h}^{-1}$ respectively.

Another important aspect of the "post-processing" is the validation of the results. In the case of the evapotranspiration, comparisons [26] have been made on a daily basis (period 1995-1996) with results provided by a hydrological model [8] applied on eight catchments spread over Belgium. The algorithms included in the hydrological model were tested at first with ground data at the Melle station. It turns out that this model is able to provide good estimates of the evapotranspiration and that it constitutes a good tool for the comparison of the AET values obtained by the present method. The agreement between the two methods is in general very satisfactory: the annual cycle and the main characteristics are very similar (correlation coefficient included between 0.85 and 0.92 ). When comparing the results for the different catchments, no clear trend appears as a function of the distance from the meteorological station of reference. This indicates that the constant daily evaporative fraction $f_{d}$ used in the present method doesn't seem to affect significantly the AET results. However, values provided by the present method are often higher (positive bias around $0.4 \mathrm{~mm} \cdot \mathrm{d}^{-1}$ ) than the corresponding results provided by the hydrological model. At this stage of the study, the net radiation assessment was suspected to be at the origin of this bias but much research was still needed to investigate this point. Since the sensitivity study has also shown that the net radiation can be responsible for a major part of the error, the emphasis will be put on this variable hereafter.

Comparison of remote sensing data with ground data must be done carefully: aerial data (with the size of the pixel) have to be compared to point data (at the location of the ground meteorological station). Moreover, the surface types are usually different, since heterogeneous vegetated surfaces are compared with the grass-covered surface of the meteorological stations. Studies dealing with footprint considerations have been (and are still) the subject of a lot of interest (e.g. [34, 57, 58, 62]). Scaling up from standpoint measurements to a landscape-scale has driven most of the recent field campaigns [60]. Studies have shown however that for moderately varying surface characteristics, the remote sensing methodologies, the parameters and the models themselves are largely scale-invariant [59]. This conclusion was also obtained for the net radiation [30].

Figure 2 presents the comparison of the surface net radiation observed at the Melle station with the aerial average, over $3 \times 3$ IR pixels around the same location, provided independently by the present method. The correlation coefficients (between 
a)
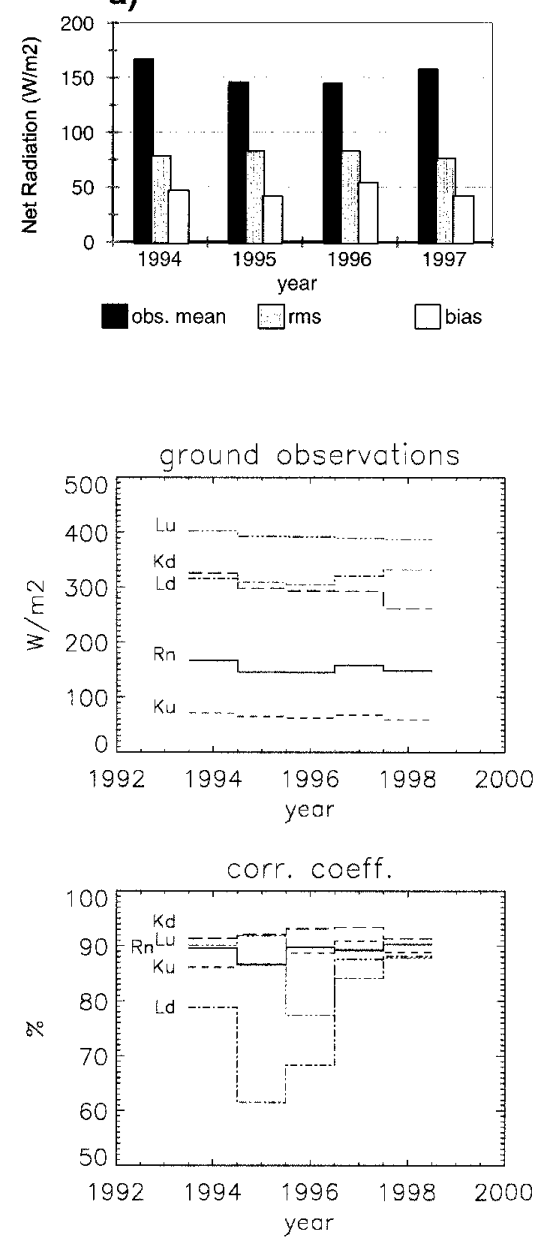

b)

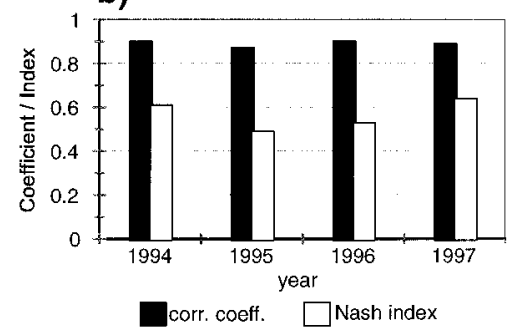

Figure 2. Net radiation. Comparison of the hourly day-light values deduced from the present method with corresponding observed values at the Melle station. Observed mean, bias, root-mean-square error (rms) (a), correlation coefficient and Nash efficiency index (b) for the 1994 to 1997 period.
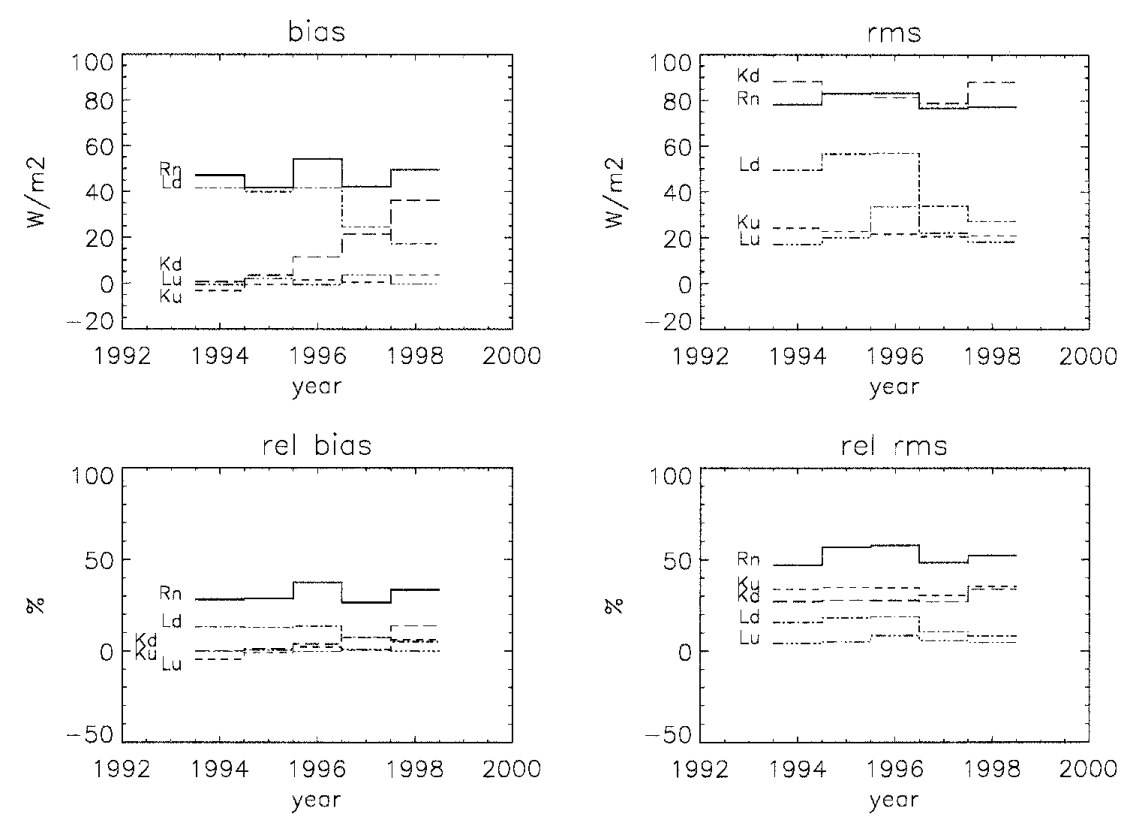

Figure 3. Comparison of hourly mean observed data and values assessed by the present method using Meteosat data. $R_{n}$ ( - ), $K_{d}(--), K_{u}(-----), L_{d}(-.-), L_{u}(-\ldots-)$.

0.87 and 0.90$)$ are very good and the Nash efficiency indices [1] showing lower values (between 0.49 and 0.64) are nevertheless satisfactory. Hourly biases are comprised between 40 and $50 \mathrm{~W} \cdot \mathrm{m}^{-2}$ which may be considered as rather high, and influence directly the accuracy of the surface turbulent fluxes and the AET. However uncertainties with the same order of magnitude are reported by Sellers et al. [60].

The hourly values of the different components of the surface radiation budget have also been inspected [21]. The correlation coefficient is very good (between 0.77 and 0.93), except for the infrared irradiance where somewhat lower correlation values (between 0.62 and 0.88 ) are obtained (Fig. 3). The quite stable bias of the net radiation appears however as the resultant of a decreasing trend showed by the infrared irradiance $L_{d}$ and a positive trend presented by the visible irradiance $K_{d}$. This latter must probably be due to an inadequate updating of the calibration parameters after the development phase (1993-1995) of the method, when only reduced manpower was available. As far as the infrared irradiance, possible causes should be searched either in the algorithms used (cloud cover assessment or the parameterisation 
used to take the clouds effects into account), or in possible erroneous ground data. The lowest bias and rms correspond to the $K_{u}$ and the $L_{u}$ components. A possible contribution comes probably from the heterogeneous character of the surface surrounding the reference station. Similar $r m s$ values are also reached by the $L_{d}$ component during the last two years. Relative bias and rms are also shown. Future research will attempt to reduce the bias of $R n$ in the present method and to update the comparison with results provided by the hydrological model.

\section{Discussion}

A method aiming to assess the evapotranspiration and the surface turbulent heat fluxes has been developed. It combines Meteosat data and ground meteorological observations. More than four years of results are available today, allowing the initiation of long term monitoring over all the Belgium territory. One important aspect of the postprocessing remains the validation of the results needed to assess the accuracy of the method and to detect parts of the methodology requiring further improvements. At present, the main liability limiting the accuracy of the results comes from the assessment of the surface net radiation. The main components to be improved in the future are the visible and infrared irradiances. A tight follow-up of the available visible calibration parameters must be ensured and a careful check of the method performances by cloudy sky conditions must be achieved. A better consideration of the effects of the clouds in the parameterisation will then possibly prove to be necessary. A careful check by experts of instruments for some ground measured data, mainly the infrared irradiance, is also desirable. However, at the time of the development of the method, with such short steps, well validated data were rather difficult to obtain. Other factors influence the quality of the results but to a lesser degree: the one site estimate of the evaporative fraction $f$ and the crude parametrisation of the heat conduction flux into the ground $Q_{g}$. Sufficient manpower is however needed to insure the mainte- nance of the hardware support and of the developed software when the results are produced in an operational way. In particular, adequate follow-up and frequent checks of the results are particularly needed.

The next generation of meteorological satellites will provide opportunities to improve the quality of the results. The launch of these satellites is scheduled in the next few years and will progressively replace the present operating satellites. Potentialities of new data that will be provided by the Meteosat Second Generation (MSG) or by the EUMETSAT Polar System (EPS) have for instance been reviewed by Desbois [16] and Bizzari [4], respectively. Despite the better space resolution offered by EPS, MSG remains more appropriate for the monitoring of quickly evolving atmospheric processes. A description of future MSG products is given by Woick et al. [68]. In particular, the SEVIRI instrument ("Spinning Enhanced Visible and Infrared Imager") is foreseen with four spectral channels in the visible (solar spectrum) and eight channels in the thermal infrared range. The present Meteosat VIS and IR channels are both split in two channels. The scanning rate of the full disk will be doubled (from one every $30 \mathrm{~min}$ in the case of Meteosat to one every 15 min for SEVIRI) and the spatial resolution will be increased (e.g. $3 \mathrm{~km}$ at the subsatellite point in the visible and the near infrared, and $1 \mathrm{~km}$ for the broadband visible channel). An onboard calibration of the IR channels is foreseen whereas a vicarious calibration will be required for the visible channels.

Moreover, to insure an optimum use of the meteorological satellite data of the new generation in Europe, EUMETSAT plans to construct a network of so-called "SAFs" (Satellite Application Facility). Each SAF will be a distributed element of the EUMETSAT ground segment and will be responsible for the provision of imagery products and services. Several SAFs are foreseen and are dedicated to well-specified subjects: Ozone-SAF, Nowcasting-SAF, Climate-SAF, Ocean-and-SeaIce-SAF, etc. The main objective of the SAF-Land has been defined as to increase the benefits from MSG and EPS data by developing appropriate techniques related to land, land-atmosphere 
interactions and biospheric applications. The development of techniques related to other recent or future instruments (MODIS, MERIS, POLDER, VEGETATION, etc.) will also be taken into account.

The method described above in the text is planned to be further developed in the Land-SAF, the evapotranspiration being one of its envisaged products. The spatial scale considered will be enlarged outside the borders of Belgium with an increased spatial resolution. An important point is that surface radiative fluxes will be produced by this SAF. Improved values of the surface net radiation will directly imply a better accuracy for the evapotranspiration results. When they will become available, the expected accuracy of the input variables will directly be used as input in the sensitivity study to assess the foreseen accuracy of the AET results. Further research will be needed to develop a robust parametrisation of $f$ and $Q_{g}$ and to check its operational applicability over a broader spatial scale. The ratio $Q_{g} / R n$ has been shown to vary during the daytime and as a function of the vegetation cover, especially for tall or sparse vegetation ([37, 50]). Different possible approaches to assess this variable (e.g. [19, 40, 41, 49]) will be examined. In a general way, the recent literature related to the assessment of the evapotranspiration and surface turbulent fluxes will be reviewed. Particular attention will be reserved for the main results of largescale field campaigns and recent research programs dealing with long term monitoring of turbulent surface fluxes (e.g. like [31, 61, 67]). New validation possibilities will also be searched; in particular, the opportunity to use data from the main flux stations in Europe or from EUROFLUX [56, 65] measurement sites over forested areas will be investigated.

Acknowledgements: The present research started under the impulse of two successive projects funded by the Belgian Federal Office for Science, Technology and Culture (Services of the Prime Minister) under its Telsat Programme (1991-1995). Thanks are due to the KNMI and in particular to Dr. F. Bosveld for providing Cabauw data used in the validation of the assessment method of the evaporative fraction. Constructive remarks of two anonymous reviewers have also been greatly appreciated.

\section{References}

[1] Aitken A.P., Assessing systematic errors in rainfall-runoff models, J. Hydrol. 20 (1973) 121-136.

[2] Anderson M.C., Norman J.M., Diak G.R., Kustas W.P., Mecikalski J.R., A two-source time-integrated model for estimating surface fluxes using thermal infrared remote sensing, Remote Sens. Environ. 60 (1997) 195-216.

[3] Bastiaanssen W.G.M., Menenti M., Feddes R.A., Holtslag A.A.M., A remote sensing surface energy balance algorithm for land (SEBAL) 1. Formulation, J. Hydrol. 212; 213 (1998) 198-212.

[4] Bizzarri B., The potential role of EPS for climate and environment monitoring, Proceedings of the 1997 EUMETSAT Meteorological Satellite Data Users' Conference, Brussels, Belgium, 29 September3 October 1997, pp. 411-421.

[5] Brisson A., Le Borgne P., Marsouin A., Moreau T., Surface irradiances calculated from Meteosat sensor data during SOFIA-ASTEX, Int. J. Remote Sens. 15 (1994) 197-203.

[6] Brutsaert W.H., Evaporation into the atmosphere Theory, History and Applications, D. Reidel Publishing Company, Dordrecht, Holland, 1982.

[7] Brutsaert W.H., Sugita M., Application of selfpreservation in the diurnal evolution of the surface energy budget to determine daily evaporation, J. Geophys. Res. 97, D17 (1992) 18377-18382.

[8] Bultot F., Dupriez G.L., Daily effective evapotranspiration from a river basin, in: WMO No. 635, Casebook on Operational Assessment of Areal Evaporation, Oper. Hydrol. Rep. 22 (1985) 80-107.

[9] Carlson T.N., Regional-scale estimates of surface moisture availability and thermal inertia using remote thermal measurements, Remote Sens. Rev. 1 (1986) 197-247.

[10] Choudhury B.J., Synergism of multispectral satellite observations for estimating regional land surface evaporation, Remote Sens. Environ. 49 (1994) 264-274.

[11] Choudhury B.J., Idso S.B., Reginato R.J., Analysis of an empirical model for soil heat flux under a growing wheat crop for estimating evapotranspiration by an infrared-temperature based energy balance equation, Agric. For. Meteorol. 39 (1987) 283-297.

[12] Crago R.D., Conservation and variability of the evaporative fraction during the daytime, J. Hydrol. 180 (1996) 173-194. 
[13] Crago R.D., Brutsaert W.H., Daytime evaporation and the self-preservation of the evaporative fraction and the Bowen ratio, J. Hydrol. 178 (1996) 241-255.

[14] Crosson W.L., Smith E.A., Cooper H.J., Estimation of surface heat and moisture fluxes over a prairie grassland 4. Impact of satellite remote sensing of slow canopy variables on performance of a hybrid biosphere model, J. Geophys. Res. 98, D3 (1993) 4979-4999.

[15] de Bruin H.A.R., Holtslag A.A.M., A simple parametrization of the surface fluxes of sensible and latent heat during daytime compared with PenmanMonteith concept, J. Appl. Meteorol. 21 (1982) 1610-1621.

[16] Desbois M., Potential of MSG for atmospheric research, Proceedings of the 1997 EUMETSAT Meteorological Satellite Data Users' Conference, Brussels, Belgium, 29 September-3 October 1997, pp. 371-374.

[17] Diak G.R., Whipple M.S., Note on estimating surface sensible heat fluxes using surface temperatures measured from a geostationary satellite during FIFE 1989, J. Geophys. Res. 100, D12 (1995) 25453-25461.

[18] Friedl M.A., Modelling land surface fluxes using a sparse canopy model and radiometric surface temperature measurements, J. Geophys. Res. 100, D12 (1995) 25435-25446.

[19] Friedl M.A., Relationships among remotely sensed data, surface energy balance, and area-averaged fluxes over partially vegetated land surfaces, J. Appl. Meteorol. 35 (1996) 2091-2103.

[20] Gellens-Meulenberghs F., Evapotranspiration and surface heat fluxes over Belgium: outcome of several years monitoring and perspectives for the next generation of meteorological satellite data, Proceedings of the International Conference and workshops on Ocean Color, Land Surfaces, Radiation Budget and Clouds, Aerosols: the Contribution of POLDER and new Generation Space borne Sensors to Global Change Studies, Méribel, France, 2, WK3, 18-22 January 1999, P16 - pp. 1-4.

[21] Gellens-Meulenberghs F., Evapotranspiration assessed by means of meteorological and satellite data: from Meteosat to MSG, Proceedings of the 1999 EUMETSAT Meteorological Satellite Data User's Conference, Copenhagen, Denmark, 6-10 September 1999, pp. 313-317.

[22] Gellens-Meulenberghs F., Roulin E., Estimating global solar radiation over Belgium using Meteosat PDUS data, Proceedings of the 10th Meteosat Users'
Meeting, Cascais, Portugal, 5-9 September 1994, pp. 507-514.

[23] Gellens-Meulenberghs F., Roulin E., An operational method based on Meteosat and Meteorological data to assess reference evapotranspiration values over Belgium, Ann. Geophys. - Part II: Hydrology, Oceans, Atmosphere \& Nonlinear Geophysics - EGS Supplement II to volume 14, 1996, C358.

[24] Gellens-Meulenberghs F., Roulin E., From numerical counts to clouds detection and evapotranspiration estimates: assessment of one year of operational application over Belgium, Proceedings of the 1996 Meteorological satellite data users' conference - geostationary systems, Vienna, Austria, 16-20 September 1996, pp. 377-384.

[25] Gellens-Meulenberghs F., Roulin E., Gosset J., Lacroix V., Operational assessment of actual evapotranspiration from Meteosat data - summary of the final report, contract T3/34/008 between the Office for Scientific, Technical and Cultural Affairs (Services of the Prime Minister) and the Royal Meteorological Institute, Belgian Scientific Research Programme on Remote Sensing by Satellite - phase three - 1993-1995 period, 1995, $17 \mathrm{p}$.

[26] Gellens-Meulenberghs F., Gellens D., Roulin E., Evapotranspiration assessment by means of Meteosat data: a comparison with values obtained by a hydrological model over Belgian catchments, Proceedings of the 1997 EUMETSAT Meteorological Satellite Data Users' Conference, Brussels, Belgium, 29 September3 October 1997, pp. 335-342.

[27] Gillies R.R., Carlson T.N., Thermal remote sensing of surface soil water content with partial vegetation cover for incorporation into climate models, J. Appl. Meteorol. 34 (1995) 745-756.

[28] Gillies R.R., Carson T.N., Cui J., Kustas W.P., Humes K.S., A verification of the 'triangle' method for obtaining surface soil water content and energy fluxes from remote measurements of the Normalised Difference Vegetation Index (NDVI) and surface radiant temperature, Int. J. Remote Sens. 18 (1997) 3145-3166.

[29] Hall G.H., Sellers P.J., First International Satellite Land Surface Climatology Project (ISLCP) Field Experiment (FIFE) in 1995, J. Geophys. Res. 100, D12 (1995) 25383-25395.

[30] Hall G.H., Huemmrich K.F., Goetz S.J., Sellers P.J., Nickeson J.E., Satellite remote sensing of surface energy balance: success, failures, and unresolved issues in FIFE, J. Geophys. Res. 97, D17 (1992) 19061-19089. 
[31] Halldin S., Gryning S.-E., Gottschalk L., Jochum A., Lundin L.-C., Van de Griend A.A., Energy, water and carbon exchange in a boreal forest landscape NOPEX experiences, Agric. For. Meteorol. 98; 99 (1999) 5-29.

[32] Huang X., Lyons T.J., Smith R.C.G., Hacker J.M., Schwerdtfeger P., Estimation of surface energy balance from radiant surface temperature and NOAA AVHRR sensor reflectances over agricultural and native vegetation, J. Appl. Meteorol. 32 (1993) 1441-1449.

[33] Hutjes R.W.A., Kabat P., Running S.W., Shuttleworth W.J., Field C., Bass B., da Silva Dias M.A.F., Avissar R., Becker A., Claussen M., Dolman A.J., Feddes R.A., Fosberg M., Fukushima Y., Gash J.H.C., Guenni L., Hoff H., Jarvis P.G., Kayane I., Krenke A.N., Changming Liu, Meybeck M., Nobre C.A., Oyebande L., Pitman A., Pielke R.A., Raupach M., Saugier B., Schulze E.D., Sellers P.J., Tenhunen J.D., Valentini R., Victoria R.L., Vörösmarty C.J., Biospheric Aspects of the Hydrological Cycle, J. Hydrol. 212; 213 (1998) 1-21.

[34] Kaharabata S.K., Schuepp P.H., Ogunjemiyo S., Shen S., Leclerc M.Y., Desjardins R.L., MacPherson J.I., Footprint consideration in BOREAS, J. Geophys. Res. 102 (1997) 29113-29124.

[35] Kalluri S.N.V., Townshend J.R.G., Doraiswamy P., A simple single layer model to estimate transpiration from vegetation using multi-spectral and meteorological data, Int. J. Remote Sens. 19 (1998) 1037-1053.

[36] Kneizys F.X., Shettle E.P., Abreu L.W., Chetwynd J.H., Anderson G.P., Gallery W.O., Selby J.E.A., Clough S.A., Users guide to LOWTRAN 7, AFGL-TR-88-0177, Environ. Res. Papers 1010 (1988) $137 \mathrm{p}$.

[37] Kustas W.P., Daughtry C.S.T., Estimation of the soil heat flux/net radiation ratio from spectral data, Agric. For. Meteorol. 49 (1990) 205-223.

[38] Kustas W.P., Norman J.M., Use of remote sensing for evapotranspiration monitoring over land surfaces, Hydrol. Sci. J. 41 (1996) 495-516.

[39] Kustas W.P., Norman J.M., Evaluation of soil and vegetation heat flux predictions using a simple twosource model with radiometric temperatures for partial canopy cover, Agric. For. Meteorol. 94 (1999) 13-29.

[40] Kustas W.P., Daughtry C.S.T., Van Oevelen P.J., Analytical treatment of the relationships between soil heat flux/net radiation ratio and vegetation indices, Remote Sens. Environ. 46 (1993) 319-330.

[41] Kustas W.P., Zhan X., Schmugge T.J., Combining optical and microwave remote sensing for mapping energy fluxes in a semiarid watershed, Remote Sens. Environ. 64 (1998) 116-131.

[42] Mahrt L., Sun J., MacPherson J.I., Jensen N.O., Desjardins R.L., Formulation of surface heat flux: application to BOREAS, J. Geophys. Res. 102, D24 (1997) 29641-29649.

[43] Mauser W., Schädlich S., Modelling the spatial distribution of evapotranspiration on different scales using remote sensing data, J. Hydrol. 212; 213 (1998) 250-267.

[44] Mecikalski J.R., Diak G.R., Norman J.M., Anderson M.C., A method for estimating regional surface sensible heating using shelter-level air temperature and upper-air data, Agric. For. Meteorol. 88 (1997) 101-110.

[45] Moran M.S., Clarke T.R., Inoue Y., Vidal A., Estimating crop water deficit using the relation between surface-air temperature and spectral vegetation index, Remote Sens. Environ. 49 (1994) 246-263.

[46] Moulin C., Lambert C.E., Poitou J., Dulac F., Long term (1983-1994) calibration of the Meteosat solar (VIS) channel using desert and oceans targets, Int. J. Remote Sens. 17 (1996) 1183-1200.

[47] Nichols W.E., Cuenca R.H., Evaluation of the evaporative fraction for the parameterization of the surface energy balance, Water Resour. Res. 29 (1993) 3681-3690.

[48] Norman J.M., Divakarla M., Goel N.S., Algorithms for extracting information from remote thermal-IR observations of the Earth's surface, Remote Sens. Environ. 51 (1995) 157-168.

[49] Norman J.M., Kustas W.P., Humes K.S., A twosource approach for estimating soil and vegetation energy fluxes from observations of directional radiometric surface temperature, Agric. For. Meteorol. 77 (1995) 263-293.

[50] Oliver S.A., Oliver H.R., Wallace J.S., Roberts A.M., Soil heat flux and temperature variation with vegetation, soil type and climate, Agric. For. Meteorol. 39 (1987) 257-269.

[51] Oncley S.P., Lenschow D.H., Campos T.L., Davis K.J., Mann J., Regional-scale surface flux observations across the boreal forest during BOREAS, J. Geophys. Res. 102, D24 (1997) 29147-29154.

[52] Pattey E., Desjardin R.L., St-Amour G., Mass and energy exchanges over a black spruce forest during key periods of BOREAS 1994, J. Geophys. Res. 102, D24 (1997) 28967-28975. 
[53] Porcù F., Levizzani V., Cloud classification using METEOSAT VIS-IR imagery, Int. J. Remote Sens. 13 (1992) 893-909.

[54] Rosema A., Using METEOSAT for operational evapotranspiration and biomass monitoring in the Sahel region, Remote Sens. Environ. 46 (1994) 27-44.

[55] Roulin E., Gellens-Meulenberghs F., Gosset J., Operational assessment of surface radiative fluxes over Belgium by means of Meteosat PDUS and meteorological data, in: Parlow E. (Ed.), Progress in Environmental Remote Sensing Research and Applications, Balkema, Rotterdam, 1996, pp. 409-416.

[56] Running S.W., Baldocchi D.P., Turner D.P., Gower S.T., Bakwin P.S., Hibbard K.A., A global terrestrial monitoring network integrating tower fluxes, flask sampling ecosystem modeling and EOS satellite data, Remote Sens. Environ. 70 (1999) 108-127.

[57] Schmid H.P., Source areas for scalars and scalar fluxes, Bound. Layer Meteorol. 67 (1994) 293-318.

[58] Schmid H.P., Lloyd C.R., Spatial representativeness and the location bias of flux footprints over inhomogeneous areas, Agric. For. Meteorol. 93 (1999) 195-209.

[59] Sellers P.J., Heiser M.D., Hall F.G., Goetz S.J., Strebel D.E., Verma S.B., Desjardins R.L., Schuepp P.M., MacPherson J.I., Effects of spatial variability in topography, vegetation cover and soil moisture on areaaveraged surface fluxes: a case study using the FIFE 1989 data, J. Geophys. Res. 100, D12 (1995) 25607-25629.

[60] Sellers P.J., Meeson B.W., Hall F.G., Asrar G., Murphy R.E., Schiffer R.A., Bretherton F.P., Dickinson R.E., Ellingson R.G., Field C.B., Huemmrich K.F., Justice C.O., Melak J.M., Roulet N.T., Schimel D.S., Try P.D., Remote sensing of land surface for studies of global change: models - algorithms - experiments, Remote Sens. Environ. 51 (1995) 3-26.

[61] Sellers P.J., Hall F.G., Kelly R.D., Black A., Baldocchi D., Berry J., Ryan M., Ranson K.J., Crill P.M., Lettenmaier D.P., Margolis H., Cihlar J.,
Newcomer J., Fitzjarrald D., Jarvis P.G., Gower S.T., Halliwell D., Williams D., Goodison B., Wickland D.E., Guertin F.E., BOREAS in 1997: experiment overview, scientific results, and future directions, J. Geophys. Res. 102, D24 (1997) 28731-28769.

[62] Sugita M., Hiyama T., Kayane I., How regional are the regional fluxes obtained from lower atmospheric boundary layer data?, Water Resour. Res. 33 (1997) 1437-1445.

[63] Suttleworth W.J., Gurney R.J., Hsu A.Y., Ormsby J.P., FIFE: The variation in energy partition at surface flux sites, in: Rango A. (Ed.), Remote Sensing and Large-Scale Global Processes, IAHS Publ., 186, Wallingford, 1989, pp. 67-74.

[64] Tanré D., Deroo C., Duhaut P., Herman M., Morcrette J.J., Perbos J., Deschamps P.Y., Description of a computer code to simulate the satellite signal in the solar spectrum: the $5 \mathrm{~S}$ code, Int. J. Remote Sens. 2 (1990) 659-668.

[65] Valentini R., Baldocchi D., Olson R., FLUXNET: A challenge that is becoming reality, Global Change Newslett. 37 (1999) 15-17.

[66] Van Hulden A.P., Wieringa J., Atmospheric boundary layer research at Cabauw, Bound. Layer Meteorol. 78 (1996) 39-69.

[67] Wilson K.B., Baldocchi D.D., Seasonal and interannual variability of energy fluxes over a broadleaved temperate deciduous forest in North America, Agric. For. Meteorol. 100 (2000) 1-18.

[68] Woick H., Schmetz J., Tjemkes S., An introduction to Meteosat Second Generation imagery and products, in: Proceedings of the 1997 EUMETSAT Meteorological Satellite Data Users' Conference, Brussels, Belgium, 29 September-3 October 1997, pp. 395-400.

[69] Zhan X., Kustas W.P., Humes K.S., An intercomparison study on models of sensible heat flux over partial canopy surfaces with remotely sensed surface temperature, Remote Sens. Environ. 58 (1996) 242-256. 